\title{
UM BREVE COMENTÁRIO \\ SOBRE OS RELATOS DE VIAGENS E AS CITAÇÕES NA OBRA OS ENSAIOS, DE MICHEL DE MONTAIGNE
}

\author{
Antonio Carlos Lopes Petean (UFOP) \\ acpetean@yahoo.com.br
}

Michel de Montaigne oferece ao leitor um modo de pensar, de ser e de escrever, como nos diz Coelho (2001), pois em pleno século XVI, ele foi uma voz contrária à perspectiva etnocêntrica de olhar o outro.

A época em que viveu Montaigne (1553-1592) foi um período de dúvidas, de incertezas e de transição. Dúvidas em relação ao saber estabelecido pela tradição, que ruiu devido a uma nova visão sobre o cosmo. Esta nova visão, proporcionada pelas revoluções científicas de Copérnico, Galileu e Bruno e, também, pelas grandes navegações, derrubaram os paradigmas teológicos sobre o geocentrismo e ergueram o heliocentrismo, colocando em dúvida o saber defendido pela igreja romana.

Mas Montaigne não aderiu ao sistema heliocêntrico de Copérnico, apenas disse que o geocentrismo e o heliocentrismo são dois sistemas rivais que não nos ajudam a desvendar a verdade sobre as coisas (SMITH, 2009).

Não era apenas a ciência que abalava o poder da igreja, a reforma protestante desencadeada por Martinho Lutero também contribuiu para colocar em dúvida o saber teológico, a infalibilidade o papa e seu poder temporal. Lutero traduziu o texto bíblico para o alemão, defendeu o livre exame da bíblia e, também, sua livre divulgação. Podemos dizer que, com Lutero, a autonomia do sujeito-leitor começou a ganhar corpo. Na análise de Marcondes:

As grandes navegações, iniciadas já no século XV, e principalmente a descoberta da América vão alterar radicalmente a própria imagem que os homens faziam da terra. As teorias de Nicolau Copérnico, Giordano Bruno, Galileu Galilei e Johannes Kepler vão revolucionar a maneira de se considerar o mundo físico, dando origem a uma nova concepção de universo. A reforma de Lutero vai abalar a autoridade universal da igreja católica no ocidente, valorizando a interpretação da Bíblia pelo próprio indivíduo. (MARCONDES, 2006, p. 159) 
$\mathrm{O}$ mundo moderno que estava nascendo nos séculos $\mathrm{XV}$ e XVI valorizou a autonomia do sujeito, que passou a ser visto como leitor e autor do conhecimento. A nascente ciência moderna de caráter empírico passa a valorizar o saber baseado na experiência sensível do indivíduo. Sendo assim, o empirismo recusa todo saber que esteja à margem ou anterior a experiência, negando o saber baseado nos escritos dos grandes homens do passado. A valorização da experiência e da observação da natureza caracterizava a ciência moderna que estava nascendo.

Foi neste contexto, que o pensador francês Michel de Montaigne se preocupou em retratar a diversidade de costumes e hábitos que os homens são capazes de criar, pois a "descoberta" da América pelos europeus lhe proporcionou material para suas observações acerca da diversidade humana. Nas palavras de Smith:

É em boa parte no interior dessa curiosidade natural sobre as múltiplas formas de vida do ser humano, tal como eles efetivamente vivem e se organizam, que a descoberta do novo mundo interessará à Montaigne (SMITH, 2009, p. 9)

Montaigne leu os relatos de viagens de Jean de Léry e André de Thevet e, também, esteve em contato com nativos americanos levados para a França por Villegagnon. De Jean de Léry, Montaigne fez uso de longas passagens da obra "Viagem à terra do Brasil", segundo Coelho (2001). Os historiadores e os relatos dos viajantes eram, portanto, a leitura preferida de Montaigne, pois lhe permitia descrever as diferentes formas de vida.

Vale destacar que os relatos de viagens foram mais significativos para Montaigne escrever seus ensaios do que a tradição Grecoromana, "pois a descoberta do novo mundo lhe abriu portas que nem mesmo a poesia e a filosofia clássica abrirão" (SMITH, 2009, p. 24). Nos ensaios, fica evidente que o encontro de Montaigne com o novo mundo ocorreu, principalmente, através dos relatos dos viajantes.

Montaigne tinha preferência pelos relatos dos "homens simples" de sua época, ao invés dos relatos dos eruditos. Segundo o filósofo, os eruditos e alguns historiadores tendem a descrever seu objeto colocando seu juízo para que o leitor concorde com as opiniões ali expressas. Sobre a preferência dos relatos dos "homens simples", vejamos o que nos diz o próprio Montaigne. 
Esse homem com quem estive era simples e grosseiro, o que é condição própria para dar testemunho verdadeiro, pois as pessoas finas observam mais as coisas, e bem mais curiosamente as glosam. Para impor sua interpretação e persuadir, acabam por alterar um pouco a História (MONTAIGNE, 2009, p. 50)

Não podemos perder de vista que, no século XVI, uma parcela dos letrados ainda mantinham vínculos com a igreja e todo saber ligado a esta instituição estava sob o crivo da dúvida e da incerteza. Portanto, é provável que Montaigne julgasse os homens cultos e finos mais presos aos costumes e hábitos que na opinião do filósofo condicionavam os relatos de viagens.

Para Montaigne, os costumes e hábitos são introduzidos em nós pela escola, por nossos pais ou pelo grupo social ao qual estamos ligados em nossa vivência cotidiana. Estes hábitos e costumes se naturalizam em nós e tecemos nossas opiniões sobre o outro a partir deles.

Montaigne fez da filosofia um instrumento para descrever a diversidade humana e não indicou através dela, qual seria a melhor forma para o homem viver em sociedade ou o melhor contrato social para ser construído. Este era o projeto filosófico de Montaigne presente em vários textos de sua obra Os Ensaios. Que segundo Coelho (2001), foi o próprio Montaigne que deu o nome para um novo gênero literário, o ensaio. Portanto, este termo foi usado pela primeira vez no século XVI e, ainda, segundo Coelho:

Ensaio, em francês essai, vem do latim exagium, que significa peso, ato de pesar; é parente próximo de exame, que originariamente tinha o significado correto de pôr na balança, pesar. Se, como gênero literário, tem antecedente em diversos tipos de composição que se apresentam como miscelânea, "discursos", "selva" ou "floresta", Montaigne foi o primeiro a usar o termo para designá-lo (COELHO, 2001, p. 34).

Os Ensaios de Montaigne abordam temas variados como a educação das crianças, o preparo para a morte, o conceito de bárbaro e a crueldade, entre outros. No ensaio "Dos Canibais", o filósofo realiza reflexões sobre os hábitos e costumes dos tupinambás, com clara intenção de criticar os próprios europeus, que vivenciavam as guerras religiosas entre católicos e protestantes. Enquanto no ensaio "Dos Coches", que também faz parte dos seus Ensaios, as reflexões se concentram na crueldade e incompreensão dos espanhóis ao se defrontarem com os povos nativos da América. Já no texto "Sobre a 
Educação das Crianças", Montaigne critica a crueldade do ensino de sua época e propõe ensinar a filosofia logo cedo para as crianças.

Ao retratar os costumes dos nativos americanos, no ensaio "Dos Canibais", Montaigne criticava ao mesmo tempo a educação, os costumes e hábitos presentes na França da sua época. Dessa forma, Montaigne acaba por julgar o velho mundo, pois ao descrever os povos do "novo mundo" ele preparava o juízo sobre o "velho mundo" (SMITH, 2009).

Sua intenção foi oferecer uma medida para julgar a França e as guerras religiosas que assolavam sua terra neste período. A França vivia um período de turbulência, pois católicos e protestantes estavam em guerra aberta e a carnificina marcou a noite de São Bartolomeu.

Mas, das primeiras linhas dos seus ensaios até as últimas, fica evidente o ceticismo do filósofo, pois, segundo Burke (2006) do primeiro ensaio até o último, Montaigne exalta a falibilidade dos sentidos e das opiniões humanas. Portanto, a filosofia se faz cética, segundo Montaigne, e deve auxiliar-nos a sermos mais prudentes e moderados, inclusive em nossas análises de outras culturas. Suas reflexões nestes textos buscarão relativizar o conceito de "povos bárbaros", conceito muito presente na literatura ocidental, desde os primórdios da civilização grega.

Portanto, como foi dito, Montaigne (2009) nos diz que somos escravos de costumes, hábitos e opiniões que circulam entre nós e aos quais aderimos através da educação, dos ensinamentos dados por nossos pais ou através do grupo social com o qual partilhamos nossa vida. Segundo o filósofo, estes hábitos e costumes nos escravizam, dominando nosso livre exame de outros povos e culturas. A tirania dos costumes nos faz julgar o outro e todo estranhamento em relação a outra cultura seria, segundo Montaigne (2009), a base de todo preconceito. Podemos dizer que este olhar sobre o outro origina o vínculo entre o etnocentrismo e o preconceito.

Para Montaigne, esta assimilação da cultura e dos hábitos teria tanta força em nós que chamamos de bárbaros todos os povos cujos costumes diferem dos nossos. Para o filósofo a tirania dos costumes e hábitos nos impede o livre exercício da razão e de construir- 
mos um juízo sobre o outro que leve em conta a própria diversidade humana. Embora o projeto filosófico da modernidade esteja amparado na autonomia do sujeito, Montaigne acaba por contestar esta possibilidade ao ver o livre exercício da razão e a livre formulação de juízos ameaçados pelos costumes e hábitos que amordaçariam os homens, gerando uma visão preconceituosa sobre o outro.

Mas o filósofo demonstra, em sua própria obra, o espírito de autonomia do início da modernidade. Montaigne usa e abusa de citações na sua obra $O s$ Ensaios, não para perpetuar um dogma, mas para ilustrar seu próprio ceticismo em relação à verdades, ou as usa como metáforas para confirmarem o que diz. Segundo Coelho (2001) as citações reiteram o que Montaigne acabou de dizer, tendo papel de interjeição ou uma função exclamativa.

Mas o próprio Montaigne também condena o uso de citações pelos escritores da época, que desejavam engrandecerem-se com elas. Nas palavras de Montaigne:

Os escritores insensatos de nosso século, que entre suas obras nulas vão semeando trechos inteiros de autores antigos para honrar a si próprios, fazem o contrário. Pois essa infinita dessemelhança de brilho dá ao que é deles um semblante pálido, tão apagado e tão feio que com isso perdem muito mais do que ganham (MONTAIGNE, 2010, p. 87)

Ao mesmo tempo em que Montaigne fez críticas ao uso excessivo de citações, ele, também, fez uso delas. E no uso de citações no decorrer dos seus ensaios, Montaigne apresenta ao seu leitor, de forma implícita, sua autonomia como sujeito-autor, numa época em que a inquisição católica atuava, ainda, com toda força. Muitas das citações são de poetas e filósofos da tradição clássica greco-romana, como Ovídio (43 a. C.-17 d. C.), Virgílio (70-19 a. C.), Lucrécio (9955 a. C.), Horácio (65-8 a. C.) e Catulo (87-57 a. C.). A escolha destes poetas é própria do espírito renascentista da época. Mas, na analise de Burke (2006), as frases colhidas destes pensadores passam a ter outra conotação nos ensaios de Montaigne e, segundo os estudos de Coelho:

Com Montaigne, passa-se a tomar o saber clássico, a tradição grecoromana, não como uma autoridade indiscutível, mas como repertório circunstancial; não como fonte de dogma, mas como ilustração (COELHO, 2001, p. 46) 
O apelo do filósofo para nos libertarmos da tirania dos costumes, hábitos e da própria opinião comum partilhada pelo grupo ao qual pertencemos é marcante nos ensaios "Dos canibais" e "Sobre a Educação das Crianças”.

Sendo assim, libertar-nos da tirania dos costumes e hábitos seria tarefa da educação segundo o filósofo. No uso de citações, o próprio Montaigne libertou-se dos costumes e hábitos da escrita de sua época que fazia das opiniões dos grandes mestres do passado, um saber inquestionável.

Se a filosofia de Montaigne não se preocupou em oferecer um modelo de organização da sociedade ou se prestou a especulações filosóficas sobre o melhor tipo de Estado que caberia aos homens construírem, podemos dizer que ele antecipou, com suas especulações filosóficas, as teses que condenam os olhares etnocêntricos. $\mathrm{Na}$ análise de Coelho (2001), Os Ensaios nos ensinam uma nova maneira de olharmos para nós, pois não eleva-nos, por preconceito ou etnocentrismo, acima de outras culturas. Podemos dizer que este olhar, que recusa o etnocentrismo, Montaigne construiu a partir das leituras que realizou dos relatos de viajantes que passaram pelo novo mundo.

\section{REFERÊNCIAS BIBLIOGRÁFICAS}

BURKE, Peter. Montaigne. São Paulo: Loyola, 2006.

COELHO, Marcelo. Montaigne. São Paulo: Publifolha, 2001.

MARCONDES, Danilo. Iniciação à história da filosofia: Dos présocráticos a Wittigenstein. São Paulo: Jorge Zahar, 2006.

MONTAIGNE, Michel de. Dos canibais. Edição organizada por Plínio Junqueira Smith. São Paulo: Alameda, 2009.

MONTAIGNE, Michel. Sobre a educação das crianças. In: . Os ensaios. São Paulo: Cia. das Letras, 2010. 